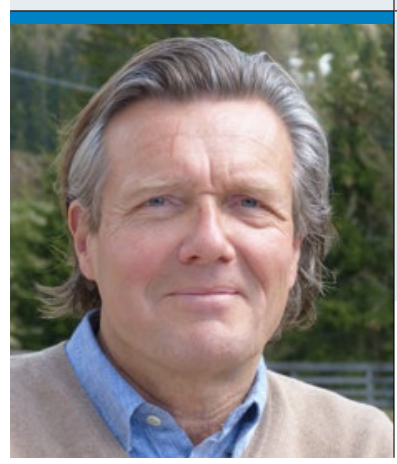

„Die Erfahrung lehrt es: Weder die Politik der neuen Bundes-

regierung noch die unserer Standesvertreter wird für uns

Niedergelassene deutliche Verbesserungen bringen."

Prof. Dr. med. Gerhard Grevers

Chefredaktion

\title{
Die Aussichten für 2018? Alles wie gehabt!
}

$\mathrm{O}$ bwohl bei Redaktionsschluss für diese Ausgabe die Koalitionsverhandlungen noch in vollem Gange sind, nach der Niedersachsenwahl ist Abgrenzung gefragt. Zu viele Gemeinsamkeiten zwischen den prospektiven Partnern auf Bundesebene gingen auf Kosten des Eigenprofils der Parteien; das kann Wählerstimmen kosten. Zumindest die Bürgerversicherung scheint uns aber wohl für die kommenden vier Jahre weiter erspart zu bleiben. Ansonsten wird der Ausgang der Bundestagswahl wie es aussieht wohl kaum Auswirkungen auf die Situation der niedergelassenen Ärzteschaft haben, zumindest keine positiven. Warum sollte es in der kommenden Legislaturperiode auch anders laufen als in den vergangenen 20 Jahren.

Was ist passiert in der Gesundheitspolitik seit der letzten Wahl? Mehr als zwei Dutzend Gesetze wurden auf den Weg gebracht, in Zeiten sprudelnder Steuereinnahmen und entsprechend voller Staatskassen konnte also viel umgesetzt werden, was gut und teuer ist und vor allem beim Wähler ankommt. Manches mag sicher sinnvoll sein, wie die Änderungen der Gesetze zur Leistungsoptimierung in der Rentenversicherung oder zur besseren Vereinbarung von Familie, Pflege und Beruf. Das GKVSelbstverwaltungsstärkungsgesetz hingegen, das dem Bundesgesundheitsministerium mehr Kontroll- und Sanktionierungsrechte gegenüber Selbstverwaltungsorganisationen und -körperschaften einräumt, haben wir im Wesentlichen eigenen Mandatsträgern zu verdanken. Gerade bei der KV hatte es in den vergangenen Jahren ja immer wieder Beispiele gegeben, bei denen die Standesvertreter ihren Aufgabenbereich fehlinterpretiert und sich eher für eigene Interessen denn für die der Allgemeinheit einsetzten (wir haben an dieser Stelle ja immer wieder über die höchst skurrilen Aktionen der betreffenden Damen und Herren berichtet und werden hier auch in Zukunft am Ball bleiben).
Ansatzpunkte zu nachhaltigen Verbesserungen für die Situation der Niedergelassenen sehe ich in keinem der Wahlprogramme. Dabei gibt es doch wirklich genug zu tun. Die Vergütungssituation im Kassenbereich ist für die HNO-Ärzte weiterhin unerträglich. Entsprechend sind die Standesvertreter gefordert, endlich einmal dafür zu sorgen, dass die Gelder zwischen den einzelnen Fachgebieten gerechter verteilt werden. Solange sich hier nichts ändert, wird sich auch die Bereitschaft zur Praxisgründung oder -übernahme nicht verbessern. Und hier geht es nicht alleine um den ländlichen Bereich .... Ich zitiere aus dem aktuellen Leserbrief eines Kollegen, der schon seit vielen Jahren in einer südwestdeutschen Großstadt praktiziert: „Ich reagiere allergisch und zunehmend wütender auf sowohl KV als auch Patienten, die mir zumuten, einen immer größer werdenden Teil meiner Zeit und Energie kostenlos der Menschheit zur Verfügung zu stellen. Strategie von uns Ärzten, unseren Berufsverbänden müsste es sein, den Patienten zu ermöglichen, alles zu fragen ... - aber ihnen den zeitlichen Aufwand auch in Rechnung stellen zu können“. Diese Ansicht kommt vom Ansatz her in zahlreichen Leserbriefen zum Ausdruck und ist den Standesvertretern, die sich ihren Einsatz ja zum Teil fürstlich vergüten lassen, seit Jahren bekannt, ohne dass sich etwas ändert. Das zeigen auch aktuell wieder die Ergebnisse der Honorarverhandlungen für 2018, die erneut enttäuschend waren. Von Seiten des KVB-Vorstandes wurde bemängelt, dass noch immer $20 \%$ der ärztlichen Leistungen nicht vergütet werden. Zufriedene Gesichter hingegen beim GKV-Spitzenverband, hier zeigte man sich angetan vom „maßvollen" Honorarabschluss.

Ihnen allen wünsche ich eine trotz allem Ärger beschauliche Vorweihnachtszeit, besinnliche Feiertage und einen guten Start ins neue Jahr 2018.

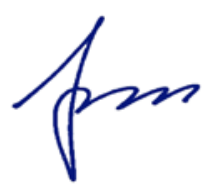

